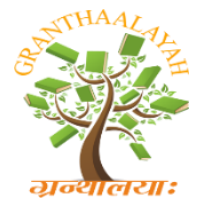

\author{
INTERNATIONAL JOURNAL OF RE
GRANTHAALAYAH \\ A knowledge Repository
}

Science

\title{
ENMG PROFILE OF PATIENTS WITH HAND PAIN COMPLAINTS
}

\author{
Shahdevi NK ${ }^{* 1}$, Kandhisa ${ }^{1}$, Machlusil H ${ }^{1}$, Neila R $^{1}$ \\ ${ }^{1}$ Neurology Department, Medical Faculty of Brawijaya University, Malang, Indonesia
}

\begin{abstract}
Introduction: Hand pain is a complaint that often found in daily practice. Electroneuromyography (ENMG) examination has pivotal role neuromuscular disorders in hand pain. This study aims to determine ENMG profile of patients with hand pain complaints also its characteristics. Methods: This research is a descriptive observational study. Data were obtained by interviewing technique conducted in neurology polyclinic General Hospital of Dr. Saiful Anwar Malang (RSSA), comprises patient characteristic and their ENMG summaries. There were a total of 58 patients with hand complaint that fulfilled inclusion criteria. ENMG was conducted to all research subjects. Results: For 10 months (April 2017 - December 2017) there were 58 patients complained of hand pain, comprised 50 new patients $(86 \%)$ and 8 old patients (13\%). A total of 41 subjects $(71 \%)$ were women and 17 subjects (29\%) were men with complaints of unilateral hand $44(76 \%)$ and bilateral $14(24 \%)$ subjects. The major age group was $45-55$ years $(70 \%)$. The average occupation that experienced by patients was housewife (63\%). Patients came with paresthesia as their most complaints $(60 \%)$ with positive Tinnel sign found in $62 \%$ of patients and hypertension $34 \%$ and DM 24\% as comorbids. ENMG was conducted to all patients with carpal tunnel syndrome (CTS) 44 patients (75\%), polyneuropathy 6 patients (10\%), de Quervain 6 patients $(10 \%)$ as results. Conclusion: The most ENMG results of patients with hand pain complaints is carpal tunnel syndrome.
\end{abstract}

Keywords: Hand Pain; CTS; Polyneuropathy; ENMG.

Cite This Article: Shahdevi NK, Kandhisa, Machlusil H, and Neila R. (2020). "ENMG PROFILE OF PATIENTS WITH HAND PAIN COMPLAINTS." International Journal of Research - Granthaalayah, 8(1), 243-249. https://doi.org/10.29121/granthaalayah.v8.i1.2020.277.

\section{Introduction}

Hand pain (wrist pain) is a symptom characterized by discomfort or pain on the wrist. The causes of wrist pain are very diverse. First thing that needs to be done is determining whether the pain is caused by trauma or non-trauma. Wrist is a complex joint that bridges hand with forearm. Wrist comprises of several bone assemblies, ligaments and tendons, nerves also blood vessels. Injury to these parts can cause wrist pain. There are diverse causes for wrist pain so that is crucial to determine whether the pain is acute, subacute or chronic (Ferguson et al., 2019). 
ENMG examination has pivotal role in neuromuscular or peripheral nervous system disorders. ENMG examination will help narrowing differential diagnosis with good clinical examination. This examination can help determining topis diagnosis, pathological diagnosis, and prognosis of peripheral nervous system disorders. CTS remains a clinical syndrome with appropriate symptoms and signs, in the presence of electrodiagnostic (EDX) abnormalities. Episodic numbness, tingling, burning or pain in the affected hand, frequent awakening at night, due to hand paresthesias, and relief of symptoms by hand shaking are characteristic symptoms of CTS. Palm pain, wrist pain or radiation proximal to the wrist may occur. The most common site of sensory symptoms is in all digits, followed by median digits only or a glove distribution (Basiri \& Katirji, 2015).

Etiology of non-trauma pain on wrist can vary. We must find out how is the pain character and look if there are any systemic symptoms. Sudden pain indicates infection, arthritis or osteonecrosis. Symptoms that come slowly are one of the characteristic of tenosynovitis, nerve entrapment syndromes. Younger patients (less than 40 years old) are more vurnerable to carpal tunnel syndrome, while elders are more susceptible to systemic diseases and degerenative processes involving wrist joint. Osteoarthritis and rheumatoid arthritis are more common in women than men. Generally, the causes of wrist pain can be divided into 3 categories, mechanic, neurological, and systemic (Wang et al., 2001).

Hand pain is a complaint that often found in daily practices, especially in neurology polyclinic General Hospital Dr. Saiful Anwar Malang. This research is expected to find out ENMG profile of patients with hand pain complaints also its characteristics

\section{Materials and Methods}

As data source, medical records of patients who were treated at neurology polyclinic General Hospital Dr. Saiful Anwar Malang during April 2017 to December 2017 period were used. They were evaluated descriptive observationally as clinical data of patients associated with hand pain. Data were also obtained by interview techniques, with characteristics of patients evaluated including age, sex, occupational type, comorbidities and time length of complaint. All of manifestasions, both signs and symptoms were noted, previous history of diseases (comorbids) and ENMG was conducted to all of research subjects.

\section{Results and Discussions}

\subsection{Characteristic of Research Subjects}

During April 2017 to December 2017 in Neurology Polyclinic General Hospital Dr. Saiful Anwar Malang found 58 cases of hand pain, consisted of 50 new cases and 8 old cases. 41 women and 17 men. The youngest age was 18 years ( 1 person) and the oldest was 79 years ( 1 person). Distribution of age and gender can be seen in table 1.

Table 1: Distribution of age and sex

\begin{tabular}{|l|c|c|c|}
\hline Age & Female (\%) & Male (\%) & Total (\%) \\
\hline $15-25$ & $1(1,8)$ & $1(1,8)$ & $2(3,4)$ \\
\hline $26-35$ & $3(5,2)$ & $3(5,2)$ & $6(10,3)$ \\
\hline
\end{tabular}




\begin{tabular}{|l|c|c|c|}
\hline $36-45$ & $5(8,6)$ & $2(3,4)$ & $7(12,0)$ \\
\hline $46-55$ & $20(34,4)$ & $5(8,6)$ & $25(43,1)$ \\
\hline $56-65$ & $9(15,5)$ & $4(6,8)$ & $13(22,4)$ \\
\hline$>65$ & $3(5,2)$ & $2(3,4)$ & $5(8,6)$ \\
\hline Total & $41(71)$ & $17(29)$ & $58(100)$ \\
\hline
\end{tabular}

Most patients were housewives (48.2\%) with descriptions of activities including washing, cooking and kneading. In patients with three other occupational types, factory employees who were also housewives for instance, they were included in occupational group that dominantly raised complaints. Job characteristics can be seen in table 2.

Table 2: Characteristics of occupation in patient with hand pain based on gender

\begin{tabular}{|l|l|c|c|c|}
\hline Occupation & Activity Description & Female (\%) & Male (\%) & Total (\%) \\
\hline House wife & Washing, cooking, teasing, typing & $29(50,0)$ & $0(0,0)$ & $29(50,0)$ \\
\hline Factory Employe & Push down, Lift heavy & $7(12,0)$ & $12(20,6)$ & $19(32,7)$ \\
\hline Teacher & Typing & $4(6,8)$ & $4(6,8)$ & $8(13,7)$ \\
\hline Collage student & Typing & $1(1,7)$ & $1(1,7)$ & $2(3,4)$ \\
\hline
\end{tabular}

\subsection{Clinical Manifestasions}

The most common clinical complaint was parasthesia, that was tingling sensation on the hands of 35 patients $(60 \%)$, followed with 29 wrist pain patients $(50 \%)$ (table 3 ).

Table 3: The Symptoms

\begin{tabular}{|l|l|l|}
\hline Symptoms & n & \% \\
\hline Parasthesia on hand & 35 & 60 \\
\hline Wrist Pain & 29 & 50 \\
\hline Numbness on hand & 22 & 37 \\
\hline Pain radiating on shoulder & 2 & 3,4 \\
\hline
\end{tabular}

Noted: one subject can have more than one symptom.

Supportive neurological examination found in hand pain patients were tinnel test $(62 \%)$ and flick test (51\%). While the least found were limited ROM (10\%) and thenar atrophy $(5.1 \%)($ table 4$)$.

Table 4: Clinical Manifestation

\begin{tabular}{|l|l|l|}
\hline Clinical Manifestation & $\mathbf{n}$ & $\boldsymbol{\%}$ \\
\hline Tinnel sign & 36 & 62,0 \\
\hline Flick sign & 30 & 51,7 \\
\hline Phalen test & 20 & 34,4 \\
\hline Prayer test & 15 & 25,8 \\
\hline Flinkestain & 8 & 13,7 \\
\hline Limited ROM & 6 & 10,3 \\
\hline Thenar atrophy & 3 & 5,1 \\
\hline
\end{tabular}

Noted: one subject can have more than one symptom. 


\subsection{Supporting Examination}

ENMG electrodiagnostic examination was performed on all patients with other examinations such as blood sugar laboratory, cholesterol and hand X-ray also ultrasound (table 5).

Table 5: Supporting Examination

\begin{tabular}{|l|l|l|}
\hline Supporting Examination & $\mathbf{n}$ & $\%$ \\
\hline ENMG & 58 & 100,0 \\
\hline Laboratories & 31 & 53,4 \\
\hline Rontgen manus & 22 & 37,9 \\
\hline USG & 9 & 15,5 \\
\hline
\end{tabular}

\subsection{Comorbidities}

The most common comorbidities were hypertension, diabetes mellitus and dyslipidemia. Not all comorbidities stood alone. Some hypertensive patients also suffered from diabetes mellitus (11 people), dyslipidemic ( 8 people), and arthritis manus (3 people) (table 6).

Table 6: Comorbids

\begin{tabular}{|l|l|l|}
\hline Komorbid & n & \% \\
\hline Hipertension & 22 & 37,9 \\
\hline Diabetes mellitus & 14 & 24,1 \\
\hline Dislipidemia & 8 & 13,7 \\
\hline Arthritis manus & 3 & 5,1 \\
\hline Herpes zooster & 1 & 1,7 \\
\hline
\end{tabular}

\subsection{Diagnosis and ENMG Profile}

From 58 patients who complained of hand pain and underwent ENMG examination, 35 patients $(60.3 \%)$ had carpal tunnel syndrome, 8 patients had polyneuropathy (13.7\%), 4 patients had dequervain (6.89\%). ENMG profile of those patients can be seen in table 7.

Table 7: Profile ENMG of patient with hand pain

\begin{tabular}{|l|c|c|}
\hline Diagnoses & Frekuensi & Persentase (\%) \\
\hline CTS & 35 & 60,35 \\
\hline De Quarvain & 4 & 6,89 \\
\hline Triger finger & 1 & 1,72 \\
\hline PNP & 8 & 13,7 \\
\hline Combination & 9 & 15,52 \\
\hline
\end{tabular}

Noted: one subject can have more than one symptom.

\subsection{Correlation of Patient CTS and Non-CTS with Affecting Factors}

Based on the research above, we conducted an analysis to determine factors that influence CTS incidence with gender, age and occupation as independent variables. For gender variable, there 
were 8 male CTS patients (15.5\%) and 34 women (58.6\%). Chi-square test obtained p value 0.023 ( $p<0.05)$ and it can be concluded that there was significant difference in CTS incidence between men and women. For age variable, there was found that the age of CTS patients in late adolescence (17-25 years) were 2 people (3.4\%), early adulthood (26-35 years) as many as 2 people (3.4\%), late adulthood ( $36-45$ years) 4 people (6.8\%), early elderly period (46-55 years) as many as 17 people (29.3\%) and late elderly (56-65 years) as many as 12 people (22.4\%) ) From chi square test that obtained $\mathrm{p}$ value 0.291 ( $\mathrm{p}>0.05$ ), it was concluded that there was no significant difference in CTS incidence between the ages. For occupation variable, there were 6 teachers (10.3\%), 29 housewives (50\%), 2 students $(3.4 \%)$ and 6 factory employees $(10.3 \%)$. From the chi square test that obtained $\mathrm{p}$ value of 0.043 ( $\mathrm{p}<0.05)$, it can be concluded that there were significant differences in CTS incidence on type of occupation.

Table 8: The Analysis result of factors that influence CTS incidence

\begin{tabular}{|l|l|l|l|}
\hline Characteristics & CTS & Non-CTS & Significance \\
\hline Gender & & & \\
Male & 8 & 8 & 0,023 \\
Female & 34 & 17 & \\
\hline Age & & & \\
$17-25$ & 2 & 0 & \\
$26-35$ & 2 & 3 & \\
$36-45$ & 4 & 3 & 0,291 \\
$46-55$ & 17 & 5 & \\
$56-65$ & 13 & 2 & \\
\hline Occupation & & & \\
Teacher & 6 & 2 & \\
Housewife & 29 & 7 & 0,043 \\
Factory Employee & 2 & 0 & \\
College Student & 6 & 6 & \\
\hline
\end{tabular}

This research involved 58 people consisting of patients with hand pain complaints who underwent ENMG, and found that ratio of female patients was more than the amount of male patients. This result corresponds with research indicating that hand pain complaints are more common in women, that is around $71 \%$. Allegedly in women there are hormonal changes such as the use of contraceptive drugs and menopause.

Based on epidemiological studies, patients with hand pain are more common to be women and it frequently occurs in their middle age (middle-aged women) before menopause. This corresponds with research we conducted that the prevalence was found more in women ranging in age from 46 to 55 years by $43.1 \%$, with housewives as their occupation. However another study stated that younger patients (less than 40 years) are more vulnerable to carpal tunnel syndrome, while elder populations are more susceptible to systemic diseases and degenerative processes (Blumenthal et al., 2006).

The most common clinical manifestasions complained in this research were tingling or paresthesia on hand by $60 \%$ although one subject could have more than one type of complaint. Based on the literatures that we obtained, wrist pain can be limited to that region as well as in general 
considering that manifestations in hand are often to be a sign of another diseases (Özdemir, 2017; Sit et al., 2017).

In this research, patients with hand pain complaints were examined by ENMG, laboratory, hand $\mathrm{x}$-ray, and some patients diagnosed with CTS were performed hand ultrasound. Electro diagnostics are useful for confirming diagnosis in patients with extended hand pain in establishing another neuropathy diagnosis. From ENMG results, there was around $60.35 \%$ that supported CTS diagnosis. This corresponds with literatures stated that carpal tunnel syndrome is the most common condition after tenosynovitis dequervain and osteoarthritis. carpal tunnel syndrome is also the most common neuropathic disease that causes hand pain symptoms, especially in middle-aged women (Lutsky et al. , 2016; Spies-Dorgelo et al., 2009).

Most comorbidities that accompanied patients with hand pain complaints in this research were hypertension by $37 \%$ and diabetes mellitus approximately by $24 \%$. Hypoparathyroidism, pregnancy, and diabetes are stated to be predisposing factors for the emergence of various peripheral neuropathy diseases. Correlation between hypertension and hand pain incidence has not been known yet, some patients with hypertension are also suffered from diabetes mellitus. Microvascular complications of diabetes mellitus can attack small blood vessels so that the circulation carrying oxygen and nutrients for nerves becomes disorganized, especially in eyes, kidneys, and peripheral nerves that can lead to peripheral diabetic neuropathy (Sözen et al., 2018).

\section{Conclusions}

Hand pain patients profile in the general hospital polyclinic of Dr. Saiful Anwar Malang for April 2017 - December 2017 period found woman as majority with range of age $52.02 \pm 16.62$. Most common found clinical manifestation was paresthesia by $60 \%$, with the most supporting neurological examination was tinnel test by $62 \%$. CTS was found to be diagnosis of patients with hand pain complaints and underwent ENMG by $60 \%$ percentage, with the most common comorbids were hypertension and diabetes mellitus $38 \%$.

There was a correlation between female gender with the probability to suffer from CTS as much as $58.6 \%$. Likewise, in terms of the occupation of women who work as housewives, $50 \%$ have a susceptibility to CTS. Seen from the age, although the incidence in productive adulthood is not common, it can be concluded that there is no correlation between age and CTS incidence.

\section{Acknowledgement}

We thank our colleagues from Neurology Study Program at Medical Faculty Brawijaya University, Malang, Indonesia.

\section{References}

[1] Basiri, K., \& Katirji, B. Practical approach to electrodiagnosis of the carpal tunnel syndrome: A review. Advanced Biomedical Research, 2015, 4(1), 50.

[2] Blumenthal, S., Herskovitz, S., \& Verghese, J. Carpal tunnel syndrome in older adults. Muscle \& Nerve, July 2006, 34(1), 78-83. 
[3] Ferguson, R., Riley, N. D., Wijendra, A., Thurley, N., Carr, A. J., \& Bjf, D. Wrist pain: a systematic review of prevalence and risk factors- what is the role of occupation and activity? BMC Musculoskeletal Disorders, December 14, 2019, 20(1), 542.

[4] Lutsky, K., Kim, N., Medina, J., Maltenfort, M., \& Beredjiklian, P. K. Hand Dominance and Common Hand Conditions. Orthopedics, May 1, 2016, 39(3), e444-e448.

[5] Özdemir, G. Working hand syndrome: A new definition of non-classified polyneuropathy condition. Medicine, June 2017, 96(25), e7235.

[6] Sit, R. W. S., Tam, W.-H., Chan, D. C. C., Yip, B. H. K., Tam, L. W. Y., Chow, L. L. Y., Chung, V. C. H., Chung, R. Y., \& Wong, S. Y. S. A Pilot Cross-Sectional Study of Postpartum Wrist Pain in an Urban Chinese Population: Its Prevalence and Risk Factors. Pain Physician, 2017, 20(5), E711-E719.

[7] Sözen, T., Başaran, N. Ç., Tınazlı, M., \& Özışık, L. Musculoskeletal problems in diabetes mellitus. European Journal of Rheumatology, December 2018, 5(4), 258-265.

[8] Spies-Dorgelo, M. N., van der Windt, D. A. W. M., Prins, A. P. A., Uitdehaag, B. M. J., \& van der Horst, H. E. Diagnosis and management of patients with hand and wrist problems in general practice. European Journal of General Practice, January 18, 2009, 15(2), 84-94.

[9] Wang, B. R., Reed, J., \& Leone, J. A Systematic Approach To A Painful Wrist. The Canadian Journal of Diagnosis, 2001, 1(August), 86-97.

*Corresponding auth or.

E-mail address: shahdevinandar@yahoo.com 